Letrônica, Porto Alegre, v. 7, n. 1, p. 66-85, jan./jun., 2014

\title{
UMA INVESTIGAÇÃO SOBRE A AQUISIÇÃO DAS REGRAS DE FORMAÇÃO DA CONSTRUÇÃO RESULTATIVA POR BILÍNGUES DE ALTA PROFICIÊNCIA DO PAR LINGUÍSTICO PORTUGUÊS DO BRASIL E INGLÊS
}

\author{
AN INVESTIGATION ON THE AQUISITION OF THE RESULTATIVE CONSTRUCTION \\ FORMATION RULES BY HIGH-PROFICIENT BRAZILIAN \\ PORTUGUESE-ENGLISH BILINGUALS
}

\author{
Cândido Samuel Fonseca de Oliveira*
}

\begin{abstract}
Resumo: 0 presente artigo relata os resultados de uma tarefa de julgamento de aceitabilidade realizada através do paradigma da estimativa de magnitude. Mais especificamente, investiga-se o comportamento de bilíngues do par linguístico português do Brasil e inglês com alta proficiência diante de sentenças em inglês - gramaticais e agramaticais - que instanciam a construção resultativa. Os resultados obtidos sugerem que esses bilíngues apresentam comportamento similar ao dos monolíngues do inglês em relação à construção resultativa gramatical, mas não em relação à agramatical, que são consideravelmente mais aceitas pelos bilíngues. Assim, este estudo corrobora a ideia de que o grau de aprendizibilidade de uma construção pode estar ligado ao tipo de relação entre a L1 e a L2 envolvidas e de que tal relação não é suficiente para fazer com que bilíngues se tornem tão sensíveis quanto falantes nativos no que tange às restrições de uma construção.

Palavras-chave: Aquisição de L2; Julgamento de aceitabilidade; Estimativa de magnitude; Construção Resultativa.
\end{abstract}

\begin{abstract}
This paper presents the results of an acceptability judgment task. The task was carried out using a magnitude estimation paradigm and aimed at investigating the behavior of highly proficient Brazilian Portuguese-English bilinguals upon reading grammatical and ungrammatical sentences in English. These sentences, in turn, instantiated a resultative construction. The results suggest that the bilinguals and the English monolinguals made similar judgments for the acceptability of the grammatical resultative construction. However, the bilinguals showed higher acceptance of ungrammatical resultative construction than the monolinguals. The present study corroborates the understanding that the level of learnability of construction may be associated with the relation between the L1 and L2 involved. Furthermore, the results suggest that this relation is not sufficient to make bilingual as sensitive to rules as native speakers.
\end{abstract}

Keywords: Second language acquisition; Acceptability judgment; Magnitude estimation; Resultative construction.

\footnotetext{
* Professor de Língua Inglesa do CEFET-MG Campus Contagem. Doutorando do Programa de Pós-Graduação em Estudos Linguísticos da Universidade Federal de Minas Gerais.
} 


\section{Introdução}

Este estudo tem por objetivo investigar a representação da construção resultativa por indivíduos falantes nativos do português brasileiro (PB) com alto nível de proficiência em inglês. Tal construção é considerada pouco licenciada, ou até mesmo inexistente em PB (BARBOSA, 2008; OLIVEIRA; SOUZA, 2012), e apresenta rica variabilidade e aceitabilidade em inglês (JACKENDOFF; GOLDBERG, 2004). Neste trabalho investiga-se a construção resultativa com o padrão sintático SN-SV-SN-SAdj ${ }^{1}$. A telicidade ${ }^{2}$ e, consequentemente, a gramaticalidade de uma sentença que instancia a construção resultativa com tal padrão sintático, é dependente do SAdj que a compõe (WECHSLER, 2001; BROCCIAS, 2003), como pode ser visto nos exemplos abaixo:

1) He wiped the table dry/*wet Ele esfregar(PASS) DET mesa seca/ molhada Ele esfregou a mesa até esta ficar seca/molhada

2) He shot the dog dead/ *wounded Ele atirar(PASS) DET cachorro morto/ ferido Ele atirou no cachorro que, consequentemente, morreu/ ficou ferido.

Oliveira e Souza (2012) foram os primeiros a investigar a aquisição desse tipo de restrição. Neste primeiro estudo, observou-se que os falantes bilíngues eram capazes de diferenciar de forma significativa a construção resultativa gramatical daquela que é tida como agramatical em língua inglesa. No entanto, o estudo desses autores não contou com a participação de um grupo controle com falantes nativos da língua inglesa, o que impossibilitou que bilíngues e monolíngues fossem comparados em termos de grau de sensibilidade a essa regra de restrição. Além disso, a estrutura testada oferecia a possibilidade de uma leitura diferente da resultativa.

${ }^{1}$ SN = Sintagma Nominal, SV = Sintagma Verbal, SAdj = Sintagma Adjetival.

2 Telicidade é a propriedade que faz um SV ter um ponto final definido. Considere as seguintes sentenças: (i) eu construí uma casa no passado e (ii) eu construí casas no passado. A ação descrita em (i) se encerrou quando a casa acabou de ser construída, ou seja, a finalização da casa é o limite final da ação. Em (ii), ao contráro, não há nada que imponha esse limite natural a ação. Por isso, diz-se que sentenças como (i) são télicas (apresentam telicidade) e sentenças como (ii) são atélicas (não apresentam telicidade). 
Dessa forma, este estudo visa complementar os achados de Oliveira e Souza (2012) através de um teste de julgamento de aceitabilidade. Este paradigma fornece dados mais refinados, com outros tratamentos estatísticos, com a presença de um grupo controle de falantes nativos do inglês e, ainda, com uma estruturação dos estímulos-alvo que as desambiguam, fazendo com que a leitura resultativa seja a única possível.

Assim como o trabalho de Oliveira e Souza (2012), este estudo é desenvolvido à luz do quadro teórico da relação conjunto e subconjunto entre línguas (MONTRUL, 2001; OKAMOTO, 2007). Este propõe que as estruturas gramaticais de uma L2 que ampliam as possibilidades de mapeamento forma-significado da L1 acarretam alta propensão à aprendizagem. Além disso, tal quadro teórico sugere que o falante bilíngue apresenta dificuldade para adquirir restrições presentes na gramática de L2. A partir de uma tarefa de julgamento de aceitabilidade utilizando o paradigma da estimativa de magnitude, foi analisado se os indivíduos bilíngues (i) aceitam a construção resultativa gramatical tanto quanto os falantes nativos do inglês e (ii) se são tão sensíveis quanto os falantes nativos do inglês em relação às restrições de formação do predicado resultativo. Os resultados sugerem que as estruturas gramaticais de uma L2 que ampliam possibilidades de mapeamento forma-significado da L1 apresentam, de fato, alta propensão à aprendizagem. Além disso, os dados apontam para o fato de tal aprendizagem não ser suficiente para fazer com que bilíngues sejam tão sensíveis quanto monolíngues no que se refere às restrições presentes na gramática da L2.

0 presente estudo será apresentado em oito seções incluindo esta introdução. $\mathrm{Na}$ seção 1, abordaremos o tema realização argumental e sua relevância para estudos de aquisição de L2. Na seção 2, haverá uma descrição da construção alvo deste estudo, a construção resultativa, e as razões pelas quais se deve tal escolha. $\mathrm{Na}$ seção 3, será apresentado o quadro teórico que levanta a suspeita de que bilíngues do par linguístico PB e inglês têm alta propensão à aprendizagem da construção resultativa e baixa propensão à aprendizagem de regras de restrição. Na seção 4, discutiremos o trabalho de Oliveira e Souza (2012), que serviu como ponto de partida para o trabalho ora descrito. Na seção 5, os materiais e métodos da pesquisa serão apresentados. $\mathrm{Na}$ seção 6, os resultados do 
experimento serão analisados e discutidos. Na última seção, concluiremos o estudo discutindo sua relevância e sugerindo estudos futuros.

\section{Realização Argumental}

Entende-se por realização argumental a manifestação sintática de um predicador e seus argumentos. 0 verbo "marchar", por exemplo, no nível semântico requer apenas um agente como argumento externo que é realizado como um SN (3). Já o verbo "enviar" precisa de um SN para realizar o argumento externo agente, um SN para realizar o argumento interno tema e um $\mathrm{SP}^{3}$ para realizar o argumento interno beneficiário (4). A estrutura argumental, contudo, é um domínio de estrutura linguística passível de variações translinguísticas (SOUZA; MELLO, 2007). Em outras palavras, as línguas podem diferir quanto às possibilidades de alternâncias de estruturas licenciadas. As traduções do inglês correspondentes a "marchar" e "enviar", "march" e "send" respectivamente, por exemplo, a despeito do fato de poderem ser encontradas em estruturas similares às das frases em PB como ilustrado em (5) e (6) - também podem aparecer em outros padrões estruturais como é apresentado em (7) e (8). Tal diferença entre PB e inglês está no fato de que a estrutura argumental de um predicado pode estar também ligada à construção envolvida (GOLDBERG, 1995; GOLDBERG; JACKENDOFF, 2004; SOUZA; MELLO, 2007).

3) Os soldados marcharam.

4) Carlos enviou um e-mail a Lucas.

5) The soldiers marched.

DET soldados marchar (PASS).

Os soldados marcharam.

6) Charles sent an e-mail to Lucca.

Charles enviar (PASS) DET e-mal para Lucca.

Charles enviou um e-mail a Lucca.

${ }^{3} \mathrm{SP}=$ Sintagma Preposicional.

Letrônica, Porto Alegre, v. 7, n. 1, p. 66-85, jan./jun., 2014 
7) The general marched the soldier to the camp. DET general marchar(PASS) DET soldados a DET campo. o general fez com que os soldados marchassem ao campo.

8) Josh sent Lucy an email. Josh enviar(PASS) Lucy DET email. Josh enviou a Lucy um email.

Segundo Goldberg (1995), a seleção dos argumentos ocorre via interação entre semântica lexical e construções. De acordo com tal visão, os verbos das sentenças (7) e (8) em inglês não mudam o seu significado para licenciar os argumentos que não estão presentes em (5) e (6). Diferentemente, assume-se que as próprias construções envolvidas também funcionam como itens lexicais independentes e, assim, os verbos não são os únicos responsáveis pela realização argumental (JACKENDOFF; GOLDBERG, 2004). Em (7), por exemplo, os dois argumentos internos preenchem a estrutura argumental da construção alternância de movimento induzido4 (Subj V Obj Obj), cuja semântica é "X causa Y mover-se para Z". Já em (8), os argumentos são realizados de acordo com a estrutura argumental da construção dativa ${ }^{5}$ (Subj V Obj Obj), cuja semântica é "X causa Y receber Z". Essas diferenças translinguísticas são interessantes para os estudos psicolinguísticos que investigam a aquisição de L2, pois elas podem, de forma sutil, afetar decisões de parseamento (JUFFS, 1998). Consequentemente, é possível que bilíngues julguem a aceitabilidade de algumas sentenças de maneira diferente em comparação com os monolíngues.

Na seção seguinte será descrita a construção alvo deste estudo: a construção resultativa.

\section{Construção resultativa}

Sentenças com o padrão sintático SN-SV-SN-SAdj em PB, tais como (9), tem um SAdj que é tipicamente interpretado como modificador de um dos SNs. Ou seja, em (9) o SAdj "limpa" pode ser interpretado ou como modificador do sujeito, dessa forma tal SAdj

\footnotetext{
${ }^{4}$ Para mais informações sobre a construção de movimento induzido, ler Souza (2011).

${ }^{5}$ Para mais informações sobre a construção ditransitiva, ler Zara (2009).
} 
caracterizaria "a garçonete" no momento da ação "esfregar"; ou pode ser entendido como modificador do objeto direto. Em tal leitura, o SAdj descreveria o estado de "a mesa" durante a ação "esfregar". A despeito da possível ambiguidade, a única leitura possível é a modificação de um dos argumentos do verbo. Trata-se de um tipo de construção que, por esta característica, é denominada descritiva.

9) A garçonete esfregou a mesa limpa.

Sentenças com estrutura similar em inglês, tais como (10), também podem ter uma leitura descritiva como descrito em Pylkkännen e McElree (2006). Como em PB, é possível interpretar o SAdj como modificador do sujeito. Dessa forma, em (10), é possível a leitura do SAdj "clean" como estado em que se encontrava o sujeito "waitress" no momento da ação "wipe". No entanto, esta não é a única interpretação possível em inglês. Em (10) também é possível se fazer uma leitura na qual a entidade referida pelo segundo SN "the table" apresenta uma nova característica "clean" em decorrência da ação "wipe". Essa é a leitura dada às sentenças que instanciam a construção resultativa. Assim, enquanto em PB o modificador normalmente se refere ao estado do SN durante uma ação, em inglês o SAdj pode se referir ao estado do SN resultante da ação verbal.

10) The waitress wiped the table clean. DET garçonete esfregar(PASS) DET mesa limpa. A garçonete esfregou a mesa até esta ficar limpa.

De acordo com Goldberg e Jackendoff (2004), a construção resultativa se destaca pela sua enorme variabilidade semântica e sintática e, por isso, pode ser dividida em subconstruções ${ }^{6}$. Neste estudo, os estímulos-alvo instanciam a subconstrução resultativa transitiva selecionada com SAdj, ilustrada pela sentença em (10). Wechsler (2001) demonstra que não é qualquer SAdj que pode compor tal subconstrução resultativa, como se pode notar nos seguintes exemplos:

\footnotetext{
6 Para informações mais detalhadas sobre todas as subconstruções resultativas, ler Jackendoff e Goldberg
} (2004). 
11) The waitress wiped the table. DET garçonete esfregar(PASS) DET mesa. A garçonete esfregou a mesa.

12) The waitress wiped the table dry/ clean. DET garçonete esfregar(PASS) DET mesa seca/ limpa. A garçonete esfregou a mesa até esta ficar seca/limpa.

13) *The waitress wiped the table wet/ dirty. DET garçonete esfregar(PASS) DET mesa molhada/ suja. A garçonete esfregou a mesa até esta ficar molhada/ suja.

De acordo com Wechsler (2001), a construção resultativa tem como uma de suas propriedades a telicidade. Sentenças com verbos durativos, tais como (11), por exemplo, são atélicas, contudo se a elas são adicionados certos SAdjs, como em (12), as mesmas passam a apresentar telicidade. Segundo o autor, um evento télico necessita apresentar três aspectos: mudança do tema, propriedade escalar e um ponto final definido. Em (12), temos um tema (table - mesa) que é transformado devido a uma ação (wipe - esfregar) e, consequentemente, adquire uma propriedade escalar (dry/clean - seca/limpa). Tal propriedade é um ponto final definido, por se tratar do ponto máximo da escala em questão, já que "seco" e "limpo" representam respectivamente 0\% líquido e 0\% sujeira. Os SAdjs em (13) (wet/dirty - molhado/sujo), ao contário, representam qualquer valor acima de $0 \%$ das mesmas propriedades e, por isso, não são capazes de impor um ponto final definido para a ação. Tal fato, segundo Wechsler (2001), faz com que a construção resultativa em (13) seja atélica e, consequentemente, agramatical. Em suma, o predicado resultativo precisa ser composto por uma propriedade escalar que represente ponto final máximo de sua escala em sentenças cujos verbos são durativos.

A seguir, explicitaremos como a aprendizagem dessas especificidades da construção resultativa do inglês por bilíngues falantes nativos do PB podem ser analisadas a partir da relação conjunto-subconjunto entre línguas. 


\section{A influência da relação conjunto-subconjunto entre línguas na aprendizagem de L2}

A aquisição de diferentes estruturas linguísticas por usuários de L2 pode apresentar durações e graus de dificuldade distintos (ELLIS, 2008). Os fatores responsáveis por essas diferenças não são apenas linguísticos, mas também cognitivos. Muitos destes são observáveis na aquisição de uma construção de L2 que não está presente em L1 ou, até mesmo, nas estratégias utilizadas por um aprendiz para expressar o sentido de uma construção típica de sua L1, mas não de sua L2. Tal fato dá à variabilidade translinguística um papel importante para estudos psicolinguísticos na aquisição de L2.

O quadro teórico sobre a relação conjunto-subconjunto entre línguas traz propostas sobre as relações entre processos cognitivos e traços de tipologia linguística. Segundo tal proposta, é possível prever quais construções acarretam problemas de aprendizibilidade a partir da disponibilidade das mesmas na L1 e na L2 (MONTRUL, 2001; OKAMOTO, 2007). Assim, a propensão de aprendizibilidade de uma construção está ligada à relação que as duas línguas têm em relação a uma construção em termos de conjunto e subconjunto.

Abaixo, ilustramos os dois contextos mais comuns em estudos elaborados à luz da relação conjunto e subconjunto entre línguas. Na figura 1, temos um contexto onde a gramática da L2 é mais ampla do que a da L1, ou seja, certos aspectos de uma construção ou estrutura estão disponíveis na L2, mas não na L1. Nesse contexto, onde a L1 é subconjunto da L2, a evidência positiva de aspectos não presentes na L1 é suficiente para que o bilíngue amplie as possibilidades de mapeamento forma-significado da L1. Em outras palavras, apenas o contato com tais aspectos é suficiente para que eles sejam aprendidos pelo bilíngue. Na figura 2, onde a L2 é subconjunto da L1, o bilíngue precisa restringir seu conhecimento gramatical ao utilizar a L2. Dessa forma, apenas a evidência positiva não é suficiente para o bilíngue adequar seu conhecimento linguístico à gramática da L2. Por isso, evidências negativas ${ }^{7}$ são necessárias e, consequentemente, a aprendizagem se torna mais difícil.

\footnotetext{
7 Neste trabalho, considera-se evidência negativa as correções ou outras ações que explicitem um erro cometido pelo falante.
} 
Figura 1: L1 subconjunto do conjunto L2

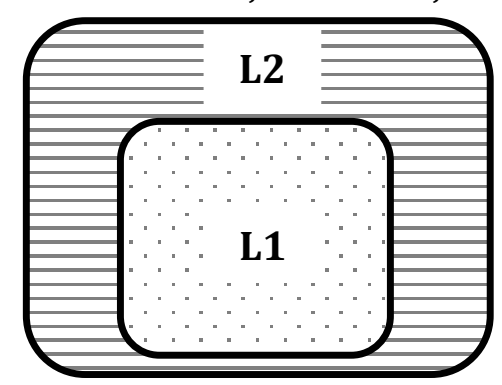

Figura 2: L2 subconjunto do conjunto L1

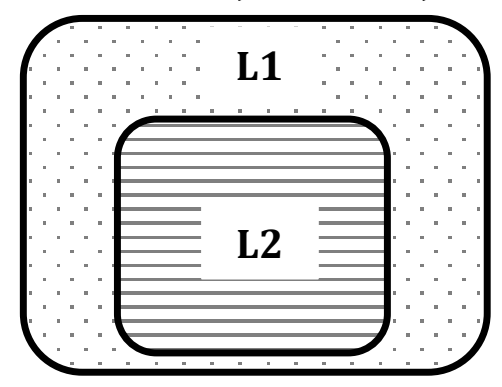

Segundo Okamoto (2007), há estudos que corroboram a maior dificuldade de aprendizibilidade em contextos como o ilustrado na figura 2. De acordo com ele, nesse caso há mais influência da L1 na L2, pois o insumo recebido na L2 parece confirmar ao bilíngue que alguns aspectos da estrutura em questão são comuns à L1 e à L2. Consequentemente, o bilíngue poderia entender que a L1 e a L2 utilizam uma sintaxe idêntica para expressar certos significados. Portanto, a falta de evidência negativa pode fazer com que os bilíngues supergeneralizem algumas regras da L2, atribuindo a uma estrutura padrões semânticos que são disponíveis apenas em L1.

A partir dessa proposta oriunda da relação conjunto e subconjunto entre línguas, é possível hipotetizar que as regras de restrição - tais como a seleção do predicado resultativo descrito anteriormente - que não se aplicam à L1 podem se impor ao bilíngue como um aspecto de díficil aquisição. Alguns estudos parecem corroborar tal hipótese. White (1991) realizou um estudo com bilíngues do par linguístico inglês e francês. A gramática do francês seria um subconjunto da gramática do inglês devido ao fato de que em francês (14), ao contrário do que ocorre em inglês (15), o dativo com objeto duplo não é permitido. De acordo com a autora, os falantes nativos do inglês aprendizes de francês com 
longo tempo de imersão na L2 ainda aceitavam sentenças como (14). Já Inagaki (2001) investigou bilíngues do par linguístico inglês e japonês e demonstrou que eles aceitam em japonês (L2) construções como (16), que são licenciadas apenas em inglês (L1). Nessa língua, não é possível formar sentenças com um SV que indica modo de movimento juntamente com um SP que indica alvo e, por isso, o japonês pode ser considerado um subconjunto do inglês. Dessa forma, ambos os estudos sugerem que até bilíngues com longa exposição à L2 podem supergeneralizar regras de L2, aceitando, nesta, padrões não licenciados.

14) *Jean a envoyé Marie des fleurs. Jean enviar(PASS) Maria DET flores. Jean enviou a Marie algumas flores.

15) John sent Mary some flowers. John enviar(PASS) Mary DET flores. John enviou a Mary algumas flores.

16) John walked to school. John andar(PASS) a escola. John foi a escola andando.

Na próxima seção, será apresentado o primeiro trabalho que visou explorar a aquisição da construção resultativa à luz da relação conjunto e subconjunto entre línguas. Além disso, serão explicitadas as razões para complementar tal estudo com este aqui proposto.

\section{Evidências prévias e o presente estudo}

A relação conjunto e subconjunto entre línguas e as evidências sobre sua aplicabilidade sugerem que, na aprendizagem de uma L2, os aspectos dependentes de evidência negativa apresentam menor propensão à aprendizagem em comparação com aqueles aspectos dependentes de evidência positiva. Neste estudo, busca-se investigar se tal hipótese pode ser aplicada à aquisição da construção resultativa. Tal investigação foi 
iniciada por Oliveira e Souza (2012), que, através de um teste de julgamento de aceitabilidade com uma Escala Likert ${ }^{8}$ de sete pontos, analisaram como bilíngues do par linguístico PB e inglês representam sentenças tais como (17) e (18). De acordo com as regras de Wechsler (2001) discutidas na seção anterior, a primeira sentença ilustra a construção resultativa, enquanto a segunda é um dos exemplos de construção resultativa cujo predicado resultativo não é licenciado, o que torna a sentença agramatical.

17) The engineer hammered the metal flat. DET engenheiro martelar(PASS) DET metal plano $O$ engenheiro martelou o metal até este ficar plano.

18) *The student cut the paper small. DET estudante cortar(PASS) DET papel pequeno O estudante cortou o papel até este ficar pequeno.

Os resultados do estudo de Oliveira e Souza (2012) indicam que os bilíngues testados diferem de forma significativa as construções gramaticais das agramaticais, apresentando maior aceitabilidade para a primeira. Tal resultado, foi interpretado como evidência de que os bilíngues adquirem as regras de restrição da L2. No entanto, ao se analisar as médias dos julgamentos, percebe-se que os bilíngues apresentam julgamentos para as duas construções que podem ser considerados relativamente próximos, como pode ser observado na tabela 1. Apesar de a diferença ser significativa, os dados trouxeram o seguinte questionamento: os bilíngues são tão sensíveis às regras de restrição quanto os falantes nativos do inglês? Com o objetivo de responder essa pergunta e de reanalisar o estudo de Oliveira e Souza (2012) propõe-se aqui um novo experimento.

\footnotetext{
${ }^{8}$ A Escala Likert é uma escala psicométrica que pode ser utilizada para se medir o nível de aceitabilidade de um indivíduo em relação a uma construção. Normalmente, utilizam-se escalas de 5 ou 7 pontos e cada um deles se refere ao grau de aceitabilidade do indivíduo em relação ao item apresentado. Assim, o valor mínimo da escala corresponde à rejeição total de um item e o valor máximo à aceitação total. 0 valor intermediário demonstraria uma posição neutra e os outros valores situados entre as extremidades e ponto médio seriam julgamentos de rejeição ou aceitação parcial do item (OLIVEIRA; SOUZA, 2012).
} 
Tabela 1 - Média de Aceitabilidade

\begin{tabular}{c|c}
\hline Tipo de sentença & Média de aceitabilidade \\
\hline Resultativa gramatical & 5,57 \\
\hline Resultativa agramatical & 4,13 \\
\hline
\end{tabular}

Fonte: Oliveira e Souza (2012)

Ao investigar a forma como Oliveira e Souza (2012) conduziram o estudo supracitado, percebeu-se que a forma como os estímulos haviam sido formulados pode ter enviesado os dados de alguma maneira. Perceba que, em (17) e em (18), as sentenças testadas possuem apenas uma interpretação em inglês. No entanto, se as traduções equivalentes de cada palavra são utilizadas na mesma ordem em PB a interpretação passa a ser diferente, uma vez que a frase se torna uma instância da construção descritiva. Dessa forma, não é possível excluir a possibilidade de que o julgamento das sentenças em L2 pelos bilíngues foi influenciado pela L1, e as sentenças tiveram uma interpretação diferente daquela possível em inglês. Assim, o presente estudo visa investigar o julgamento dos falantes bilíngues para sentenças cuja única leitura possível é a resultativa.

Em suma, o estudo ora descrito visa contrastar o comportamento de bilíngues do par linguístico PB e inglês com o comportamento dos falantes monolíngues do inglês diante de instâncias da construção resultativa que são gramaticais e outras que são agramaticais. Nenhuma das frases testadas possui leitura ambígua (resultativa e/ou descritiva), o que assegura que os resultados refletem a representação da construção resultativa. De acordo com o quadro teórico adotado, a aquisição de tal construção por esses bilíngues é dependente apenas de evidência positiva, enquanto a aquisição das regras que não licenciam os exemplos agramaticais seria dependente de evidência negativa. Dessa forma, este estudo permitirá que sejam analisadas as diferenças na aquisição dessas regras por falantes bilíngues em comparação com os falantes nativos.

Para a exploração empírica de tal assunto, foi utilizada uma tarefa de julgamento de aceitabilidade a partir do paradigma da estimativa de magnitude, no qual expomos bilíngues do par linguístico PB e inglês a dois conjuntos de estímulos. 0 primeiro conjunto foi constituído por sentenças que instanciavam a subconstrução resultativa transitiva 
selecionada com SAdj. 0 segundo grupo foi formado por sentenças que seguiam o mesmo padrão das sentenças do primeiro grupo, mas apresentavam em sua estrutura um SAdj que, segundo as regras propostas por Wechsler (2001), torna a sentença agramatical.

Levando-se em consideração que o PB é um subconjunto do inglês em relação ao padrão SN-SV-SN-SAdj e que a seleção adjetival da construção resultativa é dependente de evidência negativa, duas hipóteses são levantadas. A primeira hipótese, advinda da relação conjunto e subconjunto entre línguas, é de que (i) bilíngues do par linguístico PB e inglês altamente proficientes na L2 aprendem a construção resultativa e, consequentemente, aceitam (ou apresentariam alta aceitabilidade) as sentenças gramaticais que instanciam tal construção da mesma forma que os monolíngues do inglês. A segunda hipótese é de que tais bilíngues, devido à falta de evidência negativa (ii) não rejeitam (ou não apresentam baixa aceitabilidade), como fazem os monolíngues do inglês, as instâncias da construção resultativa com predicado resultativo não licenciado.

Passamos a seguir à descrição do procedimento experimental adotado.

\section{Materiais e métodos}

O paradigma selecionado para a realização do teste de julgamento de aceitabilidade foi a estimativa de magnitude (BARD et al., 1996; FEATHERSTON, 2005; SORACE, 2010). Essa escolha se deve ao fato de que este paradigma permite que os julgamentos sejam realizados com uma considerável liberdade. Tal característica tem como um de seus corolários uma maior sutileza e granularidade dos dados.

0 procedimento seguido pelos participantes na realização da tarefa de julgamento de aceitabilidade com a estimativa de magnitude é relativamente simples. Uma sentença padrão que permanece visível durante todo o teste é apresentada aos participantes. Eles devem julgar a aceitabilidade dessa sentença padrão com um número qualquer e utilizar tal julgamento como base para o julgamento das demais sentenças. Assim, os participantes realizam um julgamento proporcional, pois eles não apenas julgam se uma sentença é mais ou menos aceitável que a sentença padrão, mas também expressam, com quaisquer 
números, quantas vezes mais ou menos aceitável essa sentença é em relação à sentença padrão.

O experimento do estudo ora descrito foi conduzido on-line e em língua inglesa. Para isso, utilizou-se o website Survey Monkey (www.surveymonkey.com), que oferece ferramentas suficientes para experimentos que utilizam o paradigma da estimativa de magnitude. Foram criadas oito páginas com instruções sucintas, diretas e exemplificadas para a realização do experimento. Após as instruções, os estímulos eram apresentados, um em cada página, e abaixo de cada um deles havia um espaço, no qual os participantes deveriam inserir as notas que representavam o julgamento de aceitabilidade, como ilustrado na figura 3.

Figura 3: Tela com a apresentação da primeira sentença

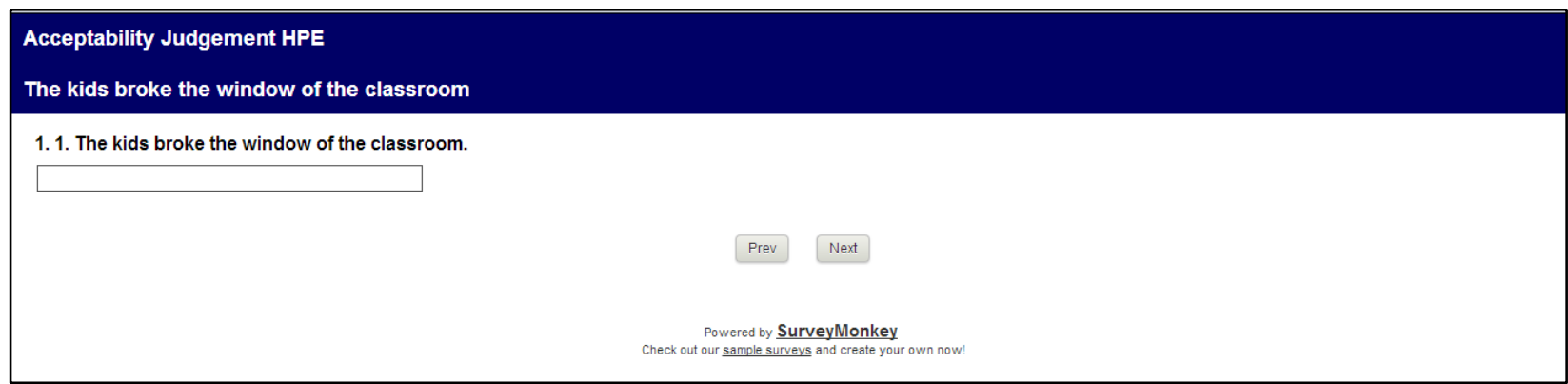

No total, o teste continha 80 sentenças para serem julgadas em relação à aceitabilidade. Houve balanceamento no que se refere ao status de gramaticalidade, de forma que $50 \%$ das sentenças eram gramaticais e 50\% das sentenças eram agramaticais. $20 \%$ das frases eram os estímulos-alvo deste estudo. Assim, havia oito sentenças que instanciavam a construção resultativa licenciada (19) e outras oito que instaciavam a construção resultativa não licenciada (20). Todos os estímulos-alvo tiveram a frequência de suas palavras controladas. Mais especificamente, optou-se prioritariamente pelo uso de 
palavras/lemas ${ }^{9}$ que estão entre as 2000 mais frequentes de acordo com o Corpus de Inglês Americano Contemporâneo (Corpus of Contemporary American English) ${ }^{10}$.

19) One of the classrooms was very dirty, so Desiree swept it clean One of the nails George bought was crooked, so he hammered it straight. Two customers complained their table was wet, so Steven wiped it dry. The tank was almost empty, so the driver filled it full. One of my friends was still sleeping, so I shook him awake. The sushi opened up on accident, so Sara rolled it closed. The glass was full, so Carol drained it half-empty. The bottle was empty, so Jones filled it half-full.

20) Chelsea had straightened her hair, but her little brother watered it curly. Lincoln's car was smelling of sandwiches, so he sprayed it perfumed. Martin didn't like the color of his new house, so he painted it beautiful. Mary's hair didn't look good, so she washed it shiny. Tara bought a new table, but her crazy brother punched it broken. Monika's hand was rough, so she moisturized it soft. Lisa didn't want to serve the rice because she had accidentally burned it dark. After the accident Erick's left arm was very weak, so he decided to work it out strong.

Todas as pessoas que realizaram o experimento aqui relatado participaram voluntariamente e assinaram o TCLE - Termo de Consentimento Livre e Esclarecido aprovado pelo COEP - Comitê de Ética e Pesquisa da Universidade Federal de Minas Gerais. No total, 50 sujeitos compuseram o grupo de participantes deste estudo. Todos os participantes eram maiores de idade e estudantes universitários. Os monolíngues do inglês eram alunos da University of Wisconsin ou da Concordia University. Os bilíngues eram em sua maioria alunos da Universidade Federal de Minas Gerais. Tratavam-se em sua maioria de bilíngues cujas trajetórias de aprendizagem da língua inglesa tiveram etapas

\footnotetext{
${ }^{9}$ Lema é o grupo de variantes (variação ortográfica e flexional) de uma mesma palavra. Lema refere-se a um grupo de palavras que são consideradas variantes da mesma palavra, diferindo somente em relação à flexão e à ortografia.

${ }^{10}$ Disponível para consulta e download em: http://www.americancorpus.org. 0 banco de palavras do Corpus of Contemporary American English contém mais de 410 milhões de palavras. Essas palavras são oriundas de textos de diferentes gêneros do período de 1990 até 2010. Para este estudo utilizou-se a lista, que é oferecida gratuitamente, com as 5000 palavras mais frequentes do inglês.
} 
transcorridas em contexto de instrução formal dentro de uma sociedade que não tem a língua inglesa como língua prevalente para interações sociais.

O grupo de participantes bilíngues do estudo foi formado por estudantes que foram avaliados com os escores mais altos em um teste de conhecimento de vocabulário em inglês - o Vocabulary Levels Test ou VLT (NATION, 1990). Tal teste é constituído por uma tarefa de ligação entre palavras e seus respectivos significados. 0 pressuposto subjacente a este modelo de triagem é que o nível de proficiência associa-se à competência no acesso lexical da L2. Cada participante teve o tempo máximo de dez minutos para a realização do teste. A limitação no tempo de realização da tarefa aumenta o efeito discriminatório do VLT. Este classifica os participantes em cinco grupos diferentes de acordo com o resultado obtido. Os grupos são organizados em ordem crescente, isto é, o grupo 1 é formado pelos falantes com menor proficiência, o grupo 5 por aqueles com maior proficiência, e os outros grupos constituem posições intermediárias. Os bilíngues selecionados para a participação neste estudo foram aqueles que compunham o grupo 5 ou o grupo 4 do VLT, bem como no estudo de Oliveira e Souza (2012).

A análise e os resultados do presente estudo são descritos na próxima seção.

\section{Análise e resultados}

Os dados oriundos do teste de julgamento de aceitabilidade com o paradigma da estimativa de magnitude foram normalizados para que fosse possível realizar o tratamento estatístico apropriado. 0 procedimento de normalização dos dados é relativamente simples. Cada nota atribuída por um participante foi subtraída pelo valor da nota mínima atribuída pelo mesmo e dividida pelo tamanho do intervalo utilizado também por ele ${ }^{11}$. Através de tal procedimento, todos os julgamentos passaram a formar uma escala de 0 a 1 . Após a normalização, os dados foram submetidos a um tratamento estatístico inferencial com vistas à verificação de efeitos de perfil linguístico em relação à aceitabilidade da construção resultativa.

\footnotetext{
${ }^{11}$ Se a menor nota de um participante foi 1 e a maior foi 20 tem-se o intervalo 19. Assim, para normalizar os julgamentos desse participante era necessário subtrair o valor 1 de cada nota e dividir o resultado por 19.
} 
A tabela 2 abaixo apresenta as médias de aceitabilidade dos dados relativos à resultativa gramatical e a resultativa agramatical pelo grupo de monolíngues do inglês e pelo grupo de bilíngues do par linguístico PB e inglês com alta proficiência.

Tabela 2 - Média de aceitabilidade da construção resultativa

\begin{tabular}{l|l|l}
\hline Tipo de sentença & $\begin{array}{l}\text { Média de aceitabilidade - } \\
\text { Monolíngues }\end{array}$ & $\begin{array}{l}\text { Média de aceitabilidade - } \\
\text { Bilíngues }\end{array}$ \\
\hline Resultativa gramatical & 0,73 & 0,69 \\
\hline Resultativa agramatical & 0,41 & 0,59 \\
\hline
\end{tabular}

As distribuições dos dados coletados foram submetidas ao teste de Shapiro-Wilk. 0 objetivo da aplicação de tal teste no estudo ora descrito era verificar se os dados haviam sido extraídos de uma população normalmente distribuída. Os resultados revelaram que não havia uma distribuição normal na população estudada. Frente à não-normalidade das distribuições observadas, realizamos uma análise pareada entre os julgamentos de aceitabilidade eliciados pelos diferentes grupos de perfis linguísticos através de um teste não-paramétrico de comparação entre tendências centrais, o teste de Mann-Whitney. Em relação às instâncias gramaticais da construção resultativa, o grupo de bilíngues com maior proficiência e o grupo de monolíngues do inglês não apresentaram diferenças significativas. Em outras palavras, os dois grupos não constituem amostras distintas $(Z=-1,153, p<0,130)$, o que está de acordo com a hipótese de que a construção resultativa apresenta alta propensão à aprendizagem. Diante das sentenças agramaticais, dissemelhantemente, os resultados indicaram que os dois grupos não constituem uma mesma amostra $(Z=-7,995$, p $<0,001)$ e, mais especificamente, que o grupo de bilíngues com alta proficiência apresenta aceitabilidade significativamente maior em comparação com o grupo de monolíngues do inglês. Assim, os dados sugerem que há uma diferença significativa entre bilíngues e monolíngues no que tange à sensibilidade a regras de restrição do predicado resultativo.

Os resultados obtidos trazem sugestões não triviais relacionadas às especificidades do falante bilíngue. 0 quadro teórico da relação conjunto e subconjunto aponta para a dificuldade do falante bilíngue em restringir na L2 o seu conhecimento gramatical oriundo 
da L1 em casos nos quais a L2 é subconjunto da L1. Os dados deste estudo sugerem que o falante bilíngue também apresenta dificuldade para adquirir regras de restrição de construções não presentes em L1, tais como a construção resultativa.

Assim, parece que a aquisição de L2 difere da aquisição de L1, entre outras coisas, em relação à capacidade do falante em aprender as restrições da língua apenas através do insumo. No âmbito do ensino de L2, essa possível diferença realça a importância da evidência negativa em sala de aula. Em outras palavras, professores de L2 devem explicitar a seus alunos as restrições presentes na L2 em vez de assumir que o insumo é o suficiente para o sucesso da aprendizagem de tais aspectos.

Na seção que segue será apresentada a conclusão deste estudo retomando os seus objetivos e resultados. Ademais, serão apresentadas sugestões para estudos futuros.

\section{Conclusão}

Este estudo teve como objetivo averiguar se a aquisição da construção resultativa segue os pressupostos da relação conjunto e subconjunto entre línguas. Os resultados de Oliveira e Souza (2012) já haviam apontado para a alta aprendizibilidade dos aspectos dependentes de evidência positiva, mas não apresentava robustez no que se referia à aprendizagem dos aspectos dependentes de evidência negativa. Com o objetivo de enriquecer os achados de tais autores, este estudo trouxe mais evidências sobre a aquisição da construção resultativa por bilíngues do par linguístico PB e inglês. Em consonância com a relação conjunto e subconjunto entre línguas, os resultados sugerem que os aspectos da construção resultativa que são dependentes apenas de evidência positiva apresentam alta propensão à aprendizagem, enquanto aqueles que são dependentes de evidência negativa se impõem ao usuário de L2 como aspecto de difícil aprendizagem. Consequentemente, os usuários de L2 com alta proficiência diferem dos falantes nativos no que tange à sensibilidade a regras de restrição do predicado resultativo.

A aquisição de construções de estrutura argumental certamente precisa de mais evidências para que as teorias a respeito do seu funcionamento sejam mais robustas. Acredita-se que ainda há muito a ser explorado e espera-se que este estudo possa ser um 
ponto de partida para vários outros sobre a aquisição de diversas construções por usuários de L2 com diferentes perfis linguísticos.

\section{Referências}

BARBOSA, Julio. A Estrutura sintática das chamadas "construções resultativas em PB". 2008. 134 f. Dissertação (Mestrado em Linguística) - Programa de Pós-Graduação em Semiótica e Linguística Geral, Faculdade de Filosofia, Letras e Ciências Humanas, Universidade de São Paulo, São Paulo, 2008.

BARD, Ellen; ROBERTSON, Dan; SORACE, Antonella. Magnitude estimation of linguistic Acceptability. Language, v. 72, p. 32-68, 1996.

ELLIS, Rod. The Study of Second Language Acquisition - $2^{\text {nd }}$ Edition. Cambridge: Cambridge University Press, 2008.

FEATHERSTON, Samuel. Magnitude estimation and what it can do for your syntax: some wh-constraints in German. Lingua, v. 115, p. 1525-1550, 2005.

GOLDBERG, Adele. Constructions: A construction grammar approach to argument structure. Chicago: University of Chicago Press, 1995.

INAGAKI, Shunji. Motion verbs with goal PPs in the L2 acquisition of English and Japanese. Studies in Second Language Acquisition, v. 23, p. 153-170, 2008.

JACKENDOFF, Ray; GOLDBERG, Adele. The English Resultative as a family of constructions. Language, v. 80, p. 523-567, 2004.

JUFFS, Alan. Some effects of first language argument structure and morphosyntax on second language sentence processing. Second Language Research, v. 14, n. 4, p. 406-424, 1998.

MONTRUL, Silvina. Agentive Verbs of Manner and Motion in Spanish and English as Second Languages. Studies in Second Language Acquisition. v. 23, p. 171-206, 2001.

NATION, Paul. Teaching and Learning Vocabulary. Boston, MA: Heinle \& Heinle, 1990.

OKAMOTO, Aya. Transfer of L1 Argument structure and morphology on L2 Japanese. Newcastle Working Papers in Linguistics, v. 12, p. 69-82, 2007.

OLIVEIRA, Cândido; SOUZA, Ricardo. Uma Exploração da Aprendizibilidade da Construção Resultativa do Inglês por Bilíngues do Par Linguístico Português do Brasil e Inglês. Confluência - Revista do Instituto de Língua Portuguesa, v. 43, p. 242-260, 2012. 
PYLKKÄNNEN, Liina; McELREE, Brian. The syntax-semantics interface: On-line composition of sentence meaning. In: TRAXLER, M; GRENSBACHER, M. (orgs.). The Handbook of Psycholinguistics - 2 ${ }^{\text {nd }}$ Edition. London/Burlington, MA: Academic Press, 2006.

SORACE, Antonella. Using Magnitude Estimation in developmental linguistics. IN: BLOM, Elma; UNSWORTH, Sharon (orgs.). Experimental Methods in Language Acquisition Research. Amsterdam/Philadelphia: John Benjamins. p. 57-72, 2010.

SOUZA, Ricardo; MELLO, Heliana. Realização argumental na língua do aprendiz de línguas estrangeiras - possibilidades de exploração da interface entre semântica e sintaxe. Revista Virtual de Estudos da Linguagem - ReVEL, v. 5, n. 8, p. 1-19, mar. 2007.

SOUZA, Ricardo. Argument structure in L2 acquisition: Language transfer re-visited in a semantics and syntax perspective. Ilha do Desterro - A Journal of English Language, Literatures in English and Cultural Studies, n. 60, p. 153-188, 2011.

WECHSLER, Stephen. An analysis of English resultatives under the event-argument homomorphism model of telicity. Proceedings of the 3rd Workshop on Text Structure. University of Texas at Austin, 2001.

WHITE, Lydia. Argument structure in second language acquisition. French Language Studies, v. 1, 189-200, 1991.

ZARA, Julia. Estudo da Expressão de Eventos de Transferência de Posse na Interlíngua de Brasileiros Aprendizes de Inglês. 2009. 159 f. Dissertação (Mestrado em Linguística Aplicada) - Programa de Pós-Graduação em Estudos Linguísticos, Universidade Federal de Minas Gerais, Belo Horizonte, 2009.

Recebido em março de 2014.

Aceito em junho de 2014. 